\title{
An expert opinion assessment of blood-feeding arthropods based on their capacity to transmit African swine fever virus in Metropolitan France
}

\author{
Claude Saegerman $^{1 *}$ (D) | Sarah Bonnet ${ }^{2}$ | Emilie Bouhsira ${ }^{3}$ | Nick De Regge ${ }^{4}$ | \\ Johanna Fite $^{5}$ | Florence Etoré $^{5}$ | Mutien-Marie Garigliany ${ }^{1}$ | Ferran Jori6* (i) | \\ Laetitia Lempereur $^{1}$ | Marie-Frédérique Le Potier ${ }^{7 *}$ (1) | Elsa Quillery ${ }^{5}$ | \\ Timothée Vergne $^{3}$ (D) | Laurence Vial ${ }^{6}$ (D)
}

${ }^{1}$ Fundamental and Applied Research for Animal and Health (FARAH) Center, University of Liège, Liège, Belgium

${ }^{2}$ UMR BIPAR, Animal Health Laboratory, INRAE, ANSES, Ecole Nationale Vétérinaire d'Alfort, Université Paris-Est, Maisons-Alfort Cedex, France

${ }^{3}$ UMR ENVT-INRA IHAP, National Veterinary School of Toulouse, Toulouse, France

${ }^{4}$ Sciensano, Scientific Direction Infectious Diseases in Animals, Bruxelles, Belgium

${ }^{5}$ French Agency for Food, Environmental and Occupational Health \& Safety, MaisonsAlfort Cedex, France

'UMR Animal, Santé, Risque et Ecosystèmes (ASTRE), CIRAD-INRAE-Université de Montpellier, Montpellier, France

${ }^{7}$ Unité de Virologie Immunologie Porcines, Laboratoire de Ploufragan/Plouzané/Niort, Anses, Ploufragan, France

\section{Correspondence}

Saegerman Claude, Fundamental and Applied Research for Animal and Health (FARAH) Center, University of Liège, B-4000 Liège, Belgium.

Email: claude.saegerman@uliege.be

\begin{abstract}
To deal with the limited literature data on the vectorial capacity of blood-feeding arthropods (BFAs) and their role in the transmission of African swine fever virus (ASFV) in Metropolitan France, a dedicated working group of the French Agency for Food, Environmental and Occupational Health \& Safety performed an expert knowledge elicitation. In total, 15 different BFAs were selected as potential vectors by the ad hoc working group involved. Ten criteria were considered to define the vectorial capacity: vectorial competence, current abundance, expected temporal abundance, spatial distribution, longevity, biting rate, active dispersal capacity, trophic preferences for Suidae, probability of contact with domestic pigs and probability of contact with wild boar. Fourteen experts participated to the elicitation. For each BFA, experts proposed a score (between 0 and 3 ) for each of the above criteria with an index of uncertainty (between 1 and 4). Overall, all experts gave a weight for all criteria (by distributing 100 marbles). A global weighted sum of score per BFA was calculated permitting to rank the different BFAs in decreasing order. Finally, a regression tree analysis was used to group those BFAs with comparable likelihood to play a role in ASF transmission. Out of the ten considered criteria, the experts indicated vectorial competence, abundance and biting rate as the most important criteria. In the context of Metropolitan France, the stable fly (Stomoxys calcitrans) was ranked as the most probable BFA to be a vector of ASFV, followed by lice (Haematopinus suis), mosquitoes (Aedes, Culex and Anopheles), Culicoides and Tabanidea. Since scientific knowledge on their vectorial competence for ASF is scarce and associated uncertainty on expert elicitation moderate to high, more studies are however requested to investigate the potential vector role of these BFAs could have in ASFV spread, starting with Stomoxys calcitrans.
\end{abstract}


KEYWORDS

African swine fever (ASF), arthropods, blood-feeding vector, culicoides, fleas, hard ticks, lice, mosquitoes, Ornithodoros, pig, sand flies, soft ticks, Stomoxys flies, Tabanidae, vectorial capacity, vectorial competence, virus, wild boar

\section{1 | INTRODUCTION}

African swine fever (ASF) is a transboundary and OIE notifiable epidemic disease caused by the African swine fever virus (ASFV), a DNA virus being the only representative of the Asfarviridae family (Galindo \& Alonso, 2017). The ASF, originating from East Africa, only affects domestic and wild Suidae (Mulumba-Mfumu et al., 2019). This viral disease, which often causes a fatal haemorrhagic syndrome in its acute form, was previously eradicated from Europe (except of Sardinia) in the 1990s. The ASFV re-emerged in Georgia in 2007 via imports of contaminated pig products from Eastern Africa or Madagascar (Rowlands et al., 2008). Subsequently, it spread to several countries of the region, including Armenia, the Russian Federation, Azerbaijan, Ukraine and Belarus (Sánchez-Vizcaíno, Mur, \& Martínez-López, 2013). In 2014, outbreaks were declared in Estonia, Latvia, Lithuania and Poland and then in Moldova in 2016 (Chenais, Ståhl, Guberti, \& Depner, 2018). Since 2017, outbreaks were reported in the Czech Republic and Romania (Chenais et al., 2018). In 2018, a first outbreak was reported in Hungary and new outbreaks occurred increasingly west of the initial outbreaks, particularly in Poland, in wild boar. Outbreaks also occurred as early as 2018 in Bulgaria and as early as 2019 in Serbia and Slovakia. In September 2018, African swine fever in wild boar was detected in Belgium (Garigliany et al., 2019). The Asian continent was also affected, with China in August 2018, and then in 2019, Mongolia in January, Taiwan and Vietnam in February, Cambodia in April, North Korea in May, Laos in June, the Philippines in July, Myanmar (Burma) in August, South Korea and East Timor in September and Indonesia in December (Plateforme ESA, 2019). With this Eurasian epidemic, ASF has become currently one of the most threatening infectious diseases of domestic pigs and wild boar worldwide, causing a considerable economic burden in affected countries (Fasina, Lazarus, Spencer, Makinde, \& Bastos, 2012; Halasa et al., 2016; Saegerman, 2018).

Based on the available evidence, direct or indirect contact between infectious and susceptible domestic pigs or wild boar, and consumption of contaminated feed are considered as the main transmission routes of ASFV for this Eurasian epidemic (MulumbaMfumu et al., 2019; Schulz, Conraths, Blome, Staubach, \& SauterLouis, 2019). However, some observations indicate that potentially also other routes of transmission may also be implicated. Indeed, in areas with high ASFV prevalence, several outbreaks of ASF have been reported in pig farms with high biosecurity (EFSA, 2010 and 2018; Olesen, Lohse, et al., 2018). These outbreaks present a seasonal pattern, with a large proportion of the cases repeatedly observed during the summer period (Pautienius et al., 2018; Podgorski
\& Smietanka, 2018). Although this seasonal pattern may be a consequence of wild boar population dynamics or commercial events, it supports the hypothesis that seasonally active and virus-contaminated arthropods could enter a pig farm with poor level of biosecurity and transmit the virus to healthy animals (Olesen, Lohse, et al., 2018).

Only, soft ticks of the genus Ornithodoros have been identified as competent vectors of ASFV (e.g. Golnar et al., 2019; SanchezBotija, 1963). Although their role in the epidemiology of the disease mainly in Africa is clear, their involvement in ASFV transmission in the Caucasus, Eastern Europe and the Baltic countries is unlikely since their presence has never been demonstrated (Guinat et al., 2016; Pereira de Oliveira et al., 2019). Furthermore, Stomoxys flies have been shown to transmit mechanically ASFV to domestic pigs under experimental conditions (Mellor, Kitching, \& Wilkinson, 1987; Olesen, Hansen, et al., 2018). ASFV has also been detected once in Haematopinus suis, a swine louse prevalent in temperate regions, collected from experimentally infected domestic pigs (Sanchez-Botija \& Badiola, 1966). It has also been proposed to perform field observations to assess vector distribution and vectorial competence in order to improve ASF control (Guinat et al., 2016).

The current knowledge on the vectorial capacity of blood-feeding arthropods (BFAs) for ASF virus transmission seems limited; therefore, this study aimed at prioritizing the potential role of 15 of the most relevant BFAs (from nine families/genera) for Metropolitan France based on a first expert knowledge elicitation.

\section{2 | MATERIALS AND METHODS}

\section{1 | Vector transmission (biological and mechanical) of ASF virus}

A vector can be defined as a BFA responsible for the active biological or mechanical transmission of a pathogen (Rodhain, 1985, 1991). The latter may be a virus, a bacteria or a parasite. Vector transmission of a pathogen therefore implies that the vector acquires the pathogen during its blood meal (or attempted blood meal) and retransmits it during a subsequent blood meal (or attempted blood meal) taken on a new host. For transmission to occur, it is therefore essential that the pathogen remains infectious in the vector (or on the mouthparts) between two successive blood meals (or two successive attempts), or even two stages (i.e. trans-stadial transmission) in the case of, for example, hard ticks that take only one blood meal per stage.

Two active vector transmission routes are considered in this study according to the definitions of Rodhain (1985 and 1991). The first is the biological transmission, which involves the achievement 
of a phase in the evolutionary cycle of the pathogen, that is its multiplication and/or transformation within the vector. The second is the active mechanical transmission, which concerns the transfer of an infectious agent from an infected host to a healthy host by means of two successive blood meals or attempted blood meals, without pathogen multiplication. In that case, the transmission then takes place through contamination of the mouthparts or crop contents of the vector with the agent remaining infectious in the residual blood present in these organs. In most cases, mechanical transmission occurs when the blood meal is interrupted due to the host's defence mechanisms in response to the painful bite (e.g. horseflies, stable flies). The vector then seeks to complete its blood meal either on the primary host or on a new host, and may thereby transmit the pathogen. This active mechanical transmission via a blood meal should be distinguished from the passive transmission via arthropods that act simply as accidental transporters.

\subsection{Vectorial competence and vectorial capacity}

Demonstrating the vectorial competence of an arthropod, that is showing its ability to become infected, to maintain or even multiply the pathogen, and then to transmit it, is a necessary but insufficient condition to conclude that the vector is capable of transmitting the pathogen under natural field conditions (Saegerman, 2018). Indeed, an arthropod could be competent based on laboratory experiments but if the arthropod never feeds on swine in nature, then it would not contribute to the transmission of ASFV. Under wild conditions, a certain number of extrinsic parameters may intervene and influence whether a competent BFA will be able to transmit a pathogen.

The combination of vectorial competence and these extrinsic factors define the vectorial capacity of a vector and reflects the efficiency of the vector to transmit a pathogen in a given susceptible population and geographical area, and at a given time (EstradaPeña, Gray, Kahl, Lane, \& Nijhof, 2013; Gubbins, Carpenter, Baylis, Wood, \& Mellor, 2008; LaDeau, Allan, Leisnham, \& Levy, 2015; Rodhain, 1985, 1991; Saegerman, Berkvens, \& Mellor, 2008). Among these parameters, vector abundance is critical: a vector with a weak vectorial competence for a pathogen, but present in high abundance, may be responsible for an efficient transmission of a disease. In addition, in certain cases, the strength of contact between vector and host is more important than vector abundance (Nash, 1944). Similarly, the dispersal capacity of the vector, whether active or passive via its hosts, is very important for the dispersal of infectious agents and thus of a disease. The ecological characteristics of the vector in terms of habitat and activity condition influence the probability of contact between the vector and the vertebrate host and thus the transmission of the pathogen to this host. Trophic preferences, representing the preference of a BFA to take its blood meal on one or more specific vertebrate host species, are also essential in determining the likelihood that the host is bitten and becomes infected. Thus, for example, a BFA shown experimentally to be a competent vector may play no role in wild conditions when its trophic preferences never bring it into contact with the reservoir host. The longevity of the vector is also important since, for all biological arthropod vectors, the higher the lifespan, the higher the number of blood meals it can take and the higher is the probability of getting infected and transmitting a disease. Finally, also the extrinsic incubation period, defined as the time needed for a pathogen to replicate and disseminate in the vector, is also an essential criterion for the biological vector transmission, which must be related to the frequency of vector blood meals.

Based on this information, 10 criteria (CO1 to C10) were considered in determining the probability of BFAs of being a vector for ASFV in Metropolitan France:

- (C1) vectorial competence;

- (C2) current vector abundance;

- (C3) future vector abundance-temporal trend (is an increase/ decrease trend in vector abundance over time expected in Metropolitan France in the coming years?);

- (C4) future vector distribution-spatial trend (is a trend towards colonizing a more extended/restricted area expected in Metropolitan France?);

- (C5) arthropod survival time (longevity);

- (C6) bite rate (number of meals per unit of time);

- (C7) dispersal capacity of the arthropod (arthropod home range);

- (C8) trophic preferences for Suidae;

- (C9) probability of BFA contact with domestic pigs;

- (C10) probability of BFA contact with wild boars.

\subsection{Expert elicitation on criteria used to assess the vectorial capacity}

Based on their experience, the authors have listed ten criteria involved in the putative vectorial capacity to transmit ASFV of the genotype II currently circulating in Europe and the selected fifteen BFAs to be considered in Metropolitan France. In addition to the proven vectors of the ASF virus (i.e. Ornithodoros sp.) and although they are not present in metropolitan France, among all the potentially other vector arthropods, only those present in metropolitan France, for which sufficient information was available regarding their bio-ecology and their role in the transmission of pathogens (ASF virus or other) were held here. Indeed, 14 families/genera of haematophagous arthropods likely to be involved in the biological or mechanical transmission of ASF virus in Metropolitan France were proposed to the experts in the framework of this elicitation: stable flies (Stomoxys calcitrans), Tabanidae, hard ticks (Ixodes, Rhipicephalus, Haemaphysalis, Hyalomma, Dermacentor), culicoides, phlebotomas, mosquitoes (Aedes, Culex, Anopheles), lice (Haematopinus suis) and fleas (Ctenocephalides felis, Pulex irritans).

An expert elicitation of knowledge was conducted, consisting in gathering the opinion of people with recognized scientific expertise and/or experience in BFAs (Appendix S1). In order to clarify the question and standardize expert's answers, a glossary was supplied 
TABLE 1 Standardized scores for each criterion involved in the estimation of the vectorial capacity of blood-feeding arthropods (BFAs) considered in the expert elicitation

\begin{tabular}{|lll|}
\hline Criteria & Score & Rating \\
\hline $\begin{array}{l}\text { Vectorial } \\
\text { competence }\end{array}$ & 0 & Null \\
\hline & 1 & Unlikely (expert opinion) \\
\hline $\begin{array}{l}\text { Current vector } \\
\text { abundance }\end{array}$ & 2 & Probable (expert opinion) \\
\hline $\begin{array}{l}\text { Future vector } \\
\text { abundance (time } \\
\text { trend) }\end{array}$ & 1 & Proven/documented \\
\hline & 1 & Null \\
\hline
\end{tabular}

\begin{tabular}{|c|c|c|}
\hline & 2 & Status quo \\
\hline & 3 & Increase \\
\hline \multirow{3}{*}{$\begin{array}{l}\text { Future vector } \\
\text { distribution (spatial } \\
\text { trend) }\end{array}$} & 1 & Decrease \\
\hline & 2 & Status quo \\
\hline & 3 & Increase \\
\hline \multirow{3}{*}{$\begin{array}{l}\text { Arthropod survival } \\
\text { time (longevity) }\end{array}$} & 1 & Short ( $<2$ weeks) \\
\hline & 2 & $\begin{array}{l}\text { Moderate ( } \geq 2 \text { weeks and } \\
<2 \text { months) }\end{array}$ \\
\hline & 3 & Long ( $\geq 2$ months) \\
\hline \multirow{3}{*}{$\begin{array}{l}\text { Bite rate (number } \\
\text { of bites per animal } \\
\text { and per unit of } \\
\text { time) }\end{array}$} & 1 & Low (<onefold by week) \\
\hline & 2 & $\begin{array}{l}\text { Moderate (between onefold by } \\
\text { day and onefold by week) }\end{array}$ \\
\hline & 3 & High (>onefold by day) \\
\hline \multirow{3}{*}{$\begin{array}{l}\text { Dispersal capacity } \\
\text { of the arthropod } \\
\text { (arthropod home } \\
\text { range) }\end{array}$} & 1 & $\operatorname{Low}(<200 \mathrm{~m})$ \\
\hline & 2 & Moderate ( $\geq 200 \mathrm{~m}$ and $\leq 1 \mathrm{~km}$ ) \\
\hline & 3 & High (>1 km) \\
\hline \multirow{3}{*}{$\begin{array}{l}\text { Trophic preferences } \\
\text { for Suidae }\end{array}$} & 1 & Low \\
\hline & 2 & Moderate \\
\hline & 3 & High \\
\hline \multirow{3}{*}{$\begin{array}{l}\text { Probability of } \\
\text { contact with } \\
\text { domestic pigs }\end{array}$} & 1 & Low \\
\hline & 2 & Moderate \\
\hline & 3 & High \\
\hline
\end{tabular}

(Continues)
TABLE 1 (Continued)

\begin{tabular}{|lll|}
\hline Criteria & Score & Rating \\
\hline $\begin{array}{l}\text { Probability of } \\
\text { contact with wild } \\
\text { boars }\end{array}$ & 1 & Low \\
& 2 & Moderate \\
& 3 & High \\
\hline
\end{tabular}

with the questionnaire (Table 1). In addition, for guidance purpose, an elicitation manual accompanied the questionnaire that each expert had to fill out (Appendix S2). The questionnaire was prepared as an Excel file (Appendix S3).

The elicited experts were first asked to provide three keywords characterizing their expertise (in descending order of importance). Second, they were asked to give a standardized score (according to Table 1) with a rating of uncertainty (according to Table 2 ) for each criterion involved in the vectorial capacity of 15 BFAs. Third, they were requested to weight each criterion involved in the vectorial capacity of each BFA considered. This relative weight was determined using the Las Vegas technique (Gore, 1987). Briefly, experts were given a number of marbles to be distributed between the ten criteria according to the importance of each criterion in the definition of vectorial capacity (100 marbles). If all criteria of vectorial capacity would have been considered equivalent by experts, each of them would have received 10 marbles.

To estimate the putative vectorial capacity of each BFA, the following formula was used:

$$
\mathrm{WS}_{\mathrm{BFAi}}=\frac{1}{100} * \sum_{j=1}^{10} S_{\mathrm{BFAi}} C_{j} * \mathrm{WC}_{j}
$$

with $\mathrm{WS}_{\mathrm{BFA}}$ being the global weighted score for BFA $i, \mathrm{~S}_{\mathrm{BFAi}} \mathrm{C}_{j}$ being the score given by the experts for the criterion $j$ and vector $i$, and $W C_{j}$, being the relative weight of criterion $j$.

We contacted 27 people having scientific knowledge and/or proven field knowledge or experience on BFAs (well-known experts on the subject, good knowledge of the Metropolitan French context). Each expert was contacted personally and responded individually to the questionnaire. Data generated by the elicitation were the scores for each criterion and the index of uncertainty given by each expert. The elicitation was performed from 1/07/2019 to 15/07/2019.

\subsection{Sensitivity analysis}

To identify whether all criteria of vectorial capacity of BFA were needed in the ranking of the 15 BFAs, a sensitivity analysis was performed. First, we started with a ranking of BFAs, considering all ten criteria of vectorial capacity (as reference) and using the median value of the global weighted score $\left(\mathrm{WS}_{\mathrm{BFA}} \mathrm{i}\right)$. Second, we ignored the different criterion of vectorial capacity one at a time and ranked all BFAs subsequently using the same methodology as presented 
above. Third, we counted how many changes in the ranking were observed, for each BFA, only considering changes of more than two ranks. A diagram was created to visualize any modification of rank induced by the withdrawal of a given criterion of vectorial capacity. In the same way, the robustness of expert elicitation was tested using the same methodology.

\section{5 | Regression analysis}

The objective of the regression tree analysis was to attribute each BFA into a homogenous group of BFAs. Indeed, each group of BFAs is statically different from another group. The principle consists in grouping BFAs in a terminal node, which is characterized by an average global weighted score with the smallest standard deviation as possible. The regression tree analysis was done using Salford Predictive Modeller (Salford Systems, San Diego, United States of America) (for more details, see e.g. Breiman, Friedman, Olshen, \& Stone, 1984; Humblet et al., 2012; Saegerman, Porter, \& Humblet, 2011). Briefly, the regression tree analysis is a non-linear and non-parametric model, fitted by binary recursive partitioning of multidimensional co-variate space (e.g. Saegerman et al., 2011). The analysis successively splits the data set into increasingly homogeneous subsets until it is stratified. The Gini index is normally used as the splitting method, and a 10 -fold cross-validation is used to test the predictive capacity of the trees obtained (Breiman et al., 1984). The regression tree analysis performs cross-validation by growing maximal trees on subsets of data, then calculating error rates based on unused portions of the data set (Breiman et al., 1984). Note that due to limited data, different taxa (species, genera, families) were considered for the evaluation of vectorial capacity.

\subsection{Statistical analysis}

The medians of the weighted vectorial capacity criteria and the global weighted scores for the different BFAs were compared using a non-parametric Kruskal-Wallis test (State SE 14.2; StataCorp, College Station, TX, USA). The limit of statistical significance of the test performed was defined as 0.05 .

\section{3 | RESULTS}

\section{1 | Response rate and skills mobilised by the experts}

The response rate among the 27 solicited experts was $52 \%$ (14 responded favourably). The skills were summarized in the Table 3.

\section{2 | Expert elicitation regarding criteria of the vectorial capacity for each blood-feeding vector}

The relative importance of the ten criteria of the vectorial capacity is depicted in Figure 1. The most important criteria for vectorial capacity were ranked in the following decreased order of the median weights obtained: vectorial competence, current vector abundance, biting rate, trophic preference for Suidae, probability of BFA contact with wild boars, probability of BFA contact with domestic pigs, dispersal capacity of the BFA, survival of the BFA, future vector abundance and future vector distribution. It should be noted that the values of quartiles 1 and 3 presented in Figure 1 are not too far from the median values, which means that overall, the experts' responses were consistent. According to the non-parametric Kruskal-Wallis test, the medians of the criteria were not equal $\left(\chi^{2}{ }_{(9 \text { degrees of freedom; } \alpha=0.05)}=64.959 ; p\right.$-value $\left.=.0001\right)$. Two of them ranked as most important (vectorial competence and current vector abundance) and four others as important with around the same weight being biting rate, trophic preferences for Suidae, probability of contact with domestic pigs and probability of contact with wild boar.
TABLE 2 Index of uncertainty used in the expert elicitation

\begin{tabular}{lll}
$\begin{array}{l}\text { Uncertainty } \\
\text { Index }\end{array}$ & Rating & Explanation \\
\hline 1 & Low & $\begin{array}{l}\text { The rating is based on the convergent results of scientific } \\
\text { studies or on a data collection system of recognized reliability }\end{array}$ \\
\hline 2 & Moderate & $\begin{array}{l}\text { The score awarded is based on a limited number of scientific } \\
\text { studies or a data collection system of limited reliability } \\
\text { and the presence of convergence between authors and/or } \\
\text { experts }\end{array}$ \\
& High & $\begin{array}{l}\text { The rating is based on: } \\
\text {-A limited number of scientific studies or a data collection } \\
\text { system of limited reliability and lack of consensus among } \\
\text { authors and/or experts; } \\
\text {-or on individual expert opinion in the absence of scientific } \\
\text { studies or a data collection system }\end{array}$ \\
& $\begin{array}{l}\text { No rating is given due to the total absence of data and expert } \\
\text { opinion }\end{array}$ \\
\hline
\end{tabular}




\begin{tabular}{|c|c|c|}
\hline Keyword 1 & Keyword 2 & Keyword 3 \\
\hline African swine fever ( 2 fold $\left.^{a}\right)$ & Acarology & Ctenocephalides felis \\
\hline Animal diseases & Coxiella-Coxiella-like & Entomology \\
\hline Flavivirus & Ecology & $\begin{array}{l}\text { Epidemiology ( } 3 \\
\text { fold }^{a} \text { ) }\end{array}$ \\
\hline Fleas & Haematophagous insects & Evolutionary biology \\
\hline Mechanical transmission & Vector-borne diseases $\left(2\right.$ fold $\left.^{\mathrm{a}}\right)$ & Laboratory diagnosis \\
\hline $\begin{array}{l}\text { Medical and Veterinary } \\
\text { Entomology }\end{array}$ & Interface & $\begin{array}{l}\text { Mechanical } \\
\text { transmission }\end{array}$ \\
\hline Parasitology & Parasitology & $\begin{array}{c}\text { Medical and } \\
\text { Veterinary }\end{array}$ \\
\hline Stomoxyinae & Stomoxys $\left(2\right.$ fold $\left.^{\mathrm{a}}\right)$ & Metropolitan France \\
\hline Tick & Tabanidae & Microbiology \\
\hline Tsetse fly & Vectorial competence & Ticks $\left(2\right.$ fold $\left.^{a}\right)$ \\
\hline Virology & Vectors & $\begin{array}{l}\text { Vector borne } \\
\text { diseases }\end{array}$ \\
\hline Wild boar & Virology-immunology & Wild boar \\
\hline Zoonoses & & \\
\hline
\end{tabular}

TAB LE 3 Keywords related to the skills of elicited experts (decreasing order of importance)

${ }^{a}$ Number of occurrences of a specific keyword.

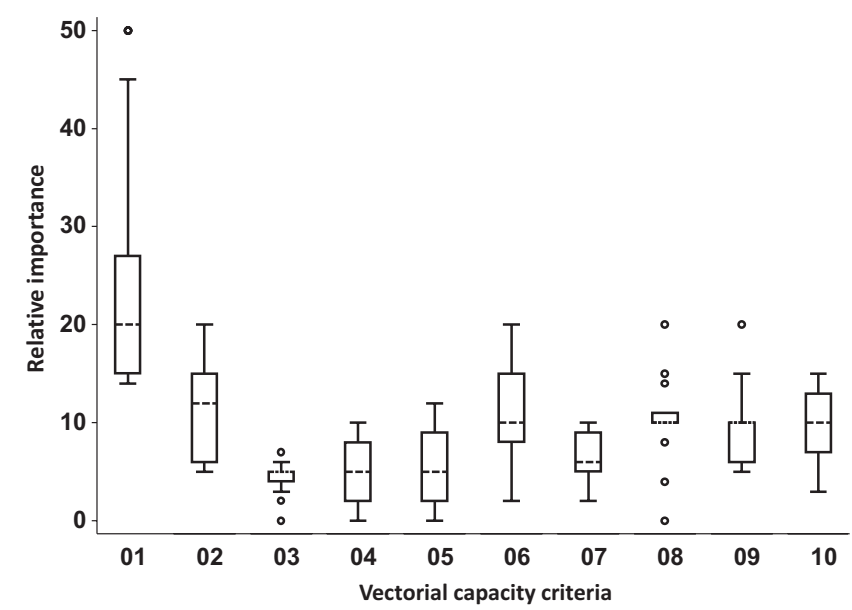

FIGURE 1 Relative importance of the ten criteria defining the vectorial capacity of blood-feeding arthropods for ASFV (box plot). The dashed line represents the median of the score distribution between the different experts; the solid lines below and above each rectangle represent, respectively, the first and the third quartiles; adjacent lines to the whiskers represent the limits of the 95\% confidence interval; and small circles represent outside values. The criteria evaluated are represented by numbers: vectorial competence (01); current vector abundance (02); future vector abundance-time trend (03); future vector distribution-spatial trend (04); arthropod survival time-longevity (05); biting rate expressed as number of meals/unit of time (06); arthropod home range or dispersal capacity (07); trophic preferences for Suidae (08); probability of contact with domestic pigs (09); and probability of contact with wild boar (10).

The relative importance of each BFA and its associated uncertainty median index for each criterion of vectorial capacity is presented in Table 4. On the whole, for all criteria confounded, the median uncertainty index is, in most cases, in the order of 2 (moderate index on a scale from 1 to 4), except for Culicoides and fleas (Ctenocephalides felis, Pulex irritans), for which it is 3 (high index on a scale from 1 to 4). However, some differences were observed for the associated uncertainty median indexes to criteria of vectorial capacity for all the considered BFAs. Higher uncertainty was observed for vectorial competence (Figure 2).

\section{3 | Global weighted estimate of the vectorial capacity of each blood-feeding arthropod}

According to the non-parametric Kruskal-Wallis test, the medians of the global weighted scores for the different BFAs are not equal $\left(\chi_{(14 \text { degrees of freedom; } \alpha=0.05)}^{2}=59.935 ; p\right.$-value $\left.=.0001\right)$. Five of them were ranked to have the highest probability to play a role in ASFV transmission in Metropolitan France, being Stomoxys calcitrans, Haematopinus suis, the mosquitoes (genera Aedes, Culex and Anopheles), Culicoides and Tabanidae (Figure 3).

\subsection{Sensitivity analysis of the impact of criteria of vectorial capacity on the final ranking of blood- feeding arthropods}

The sensitivity analysis consisted in the comparison of the ranking of BFAs based on all ten criteria of vectorial capacity as a reference with the ranking of BFAs when one of the ten criteria of vectorial capacity was removed from the analysis. This sensitivity analysis indicated that three criteria are highly important in the outcome of the ranking: vectorial competence (C1), current vector 


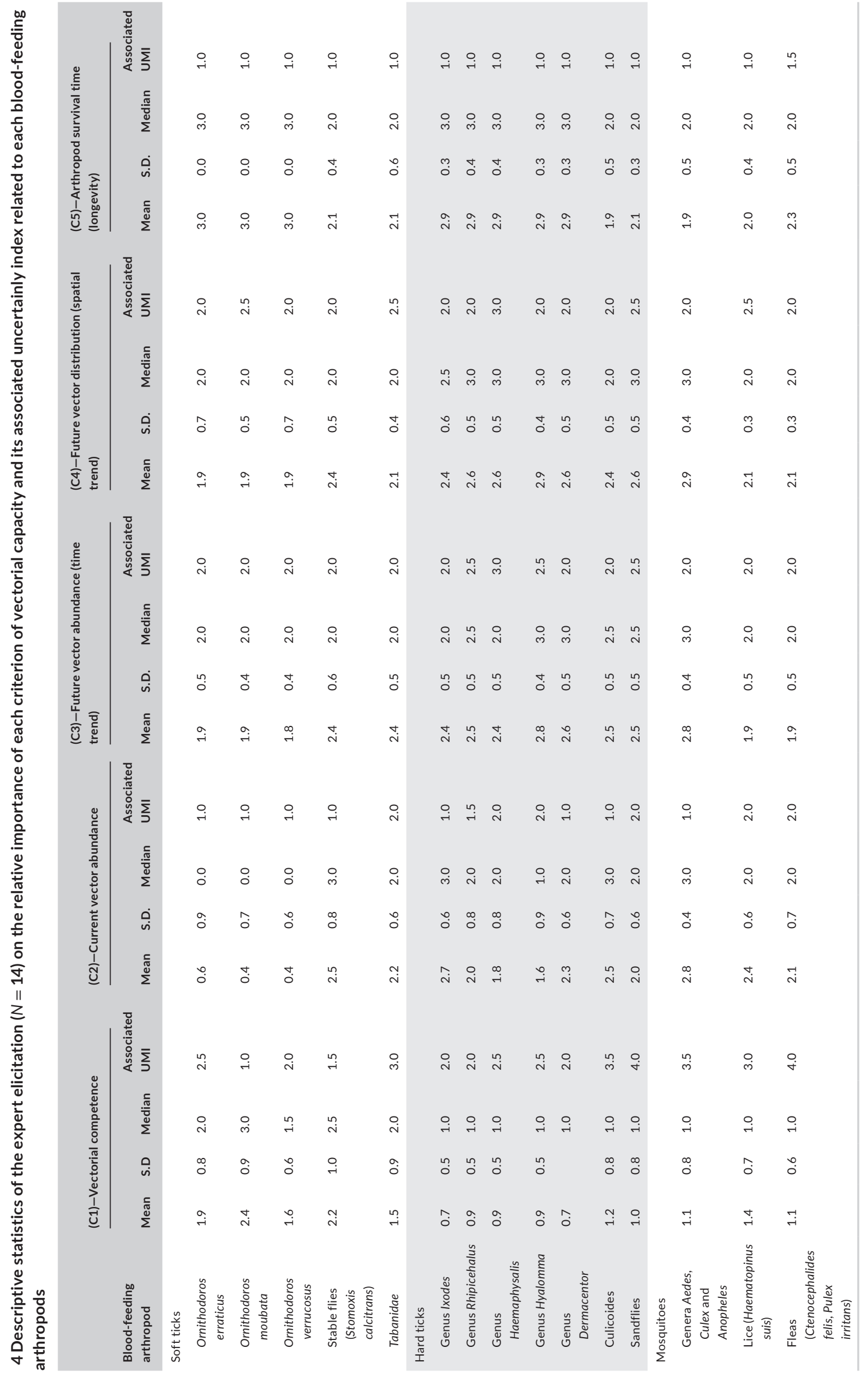




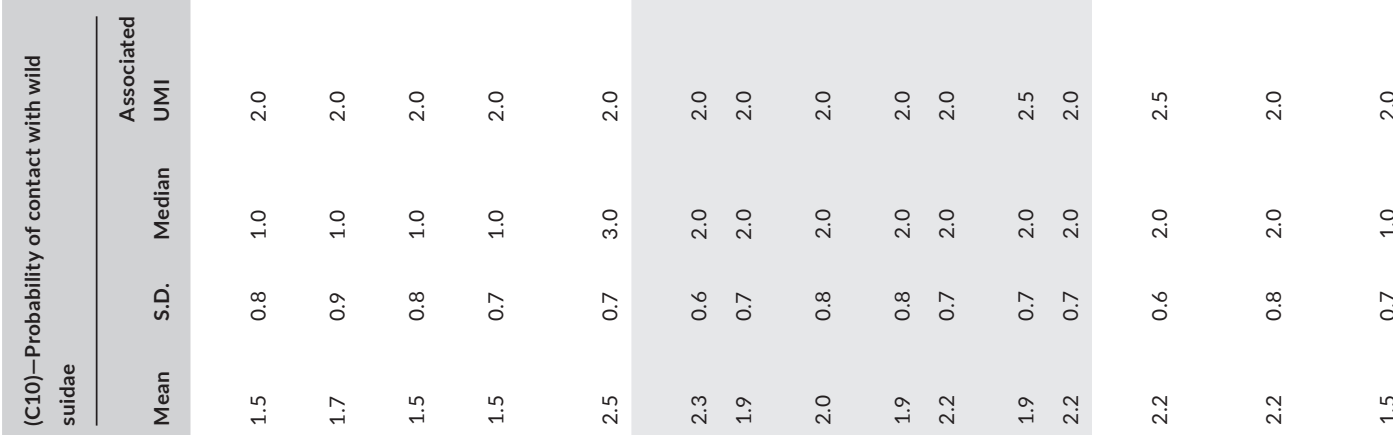

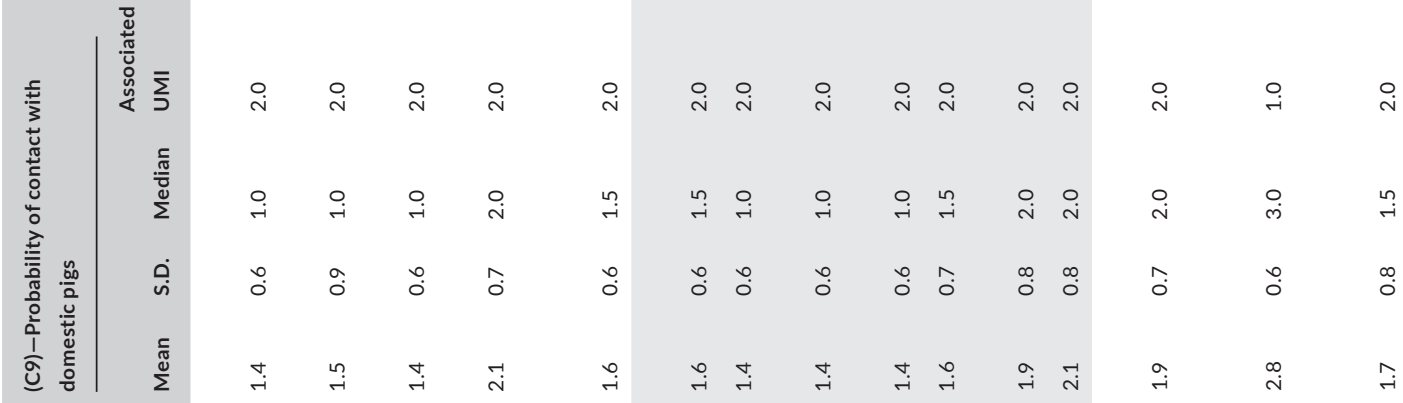

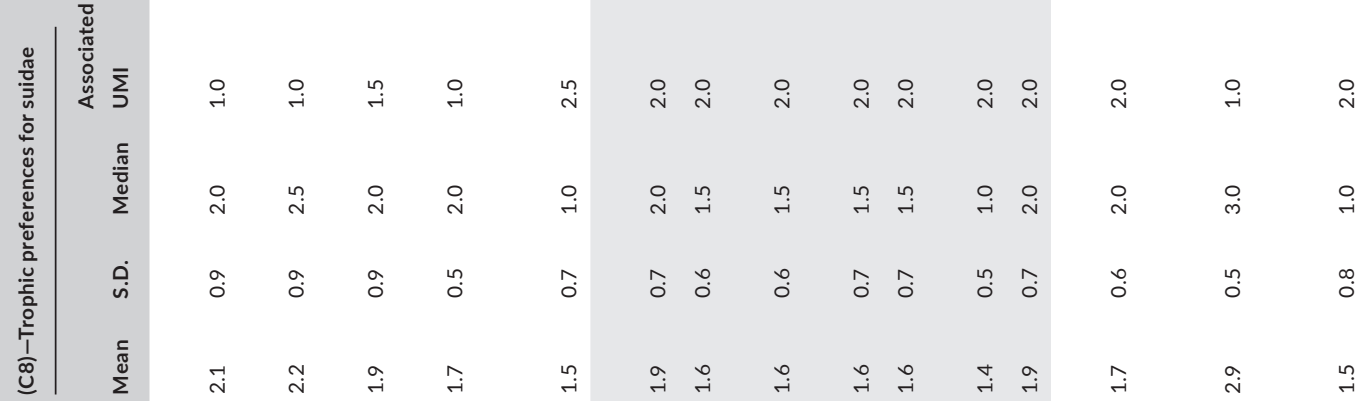

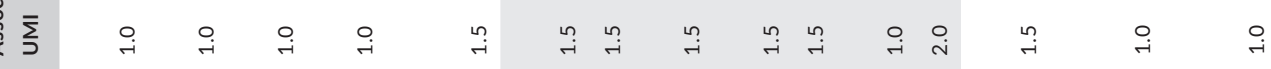

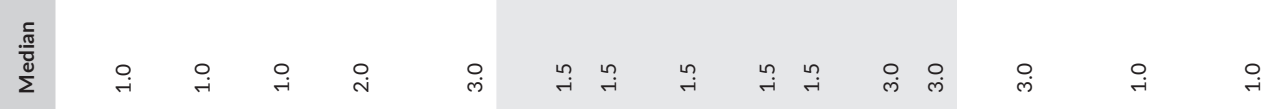

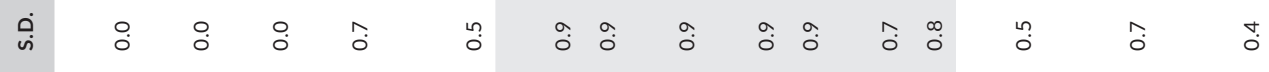

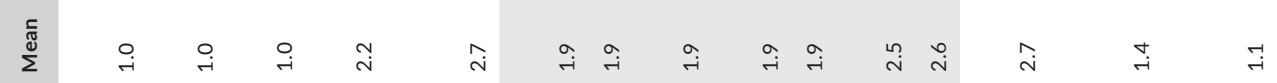

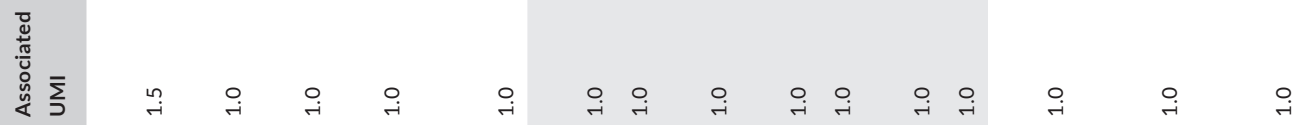

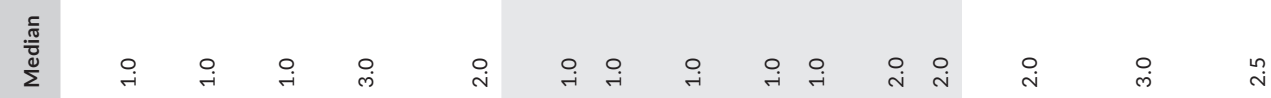

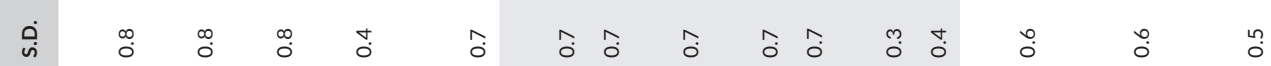

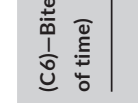
๘ $\stackrel{\circ}{i} \quad \stackrel{\circ}{i} \quad \stackrel{\circ}{i} \stackrel{\infty}{\sim}$

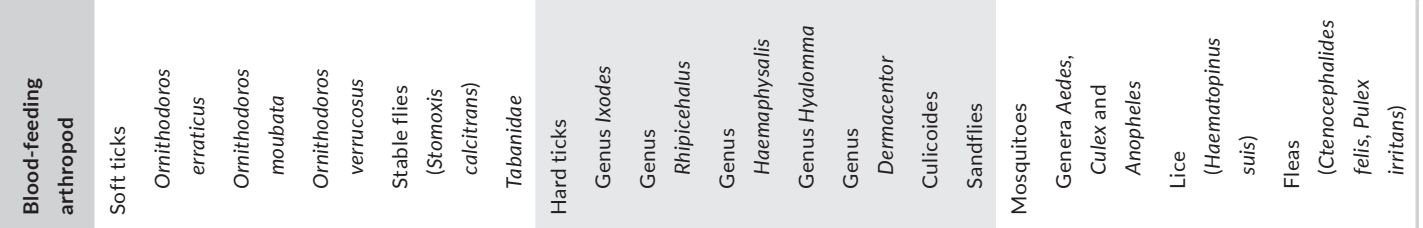


abundance (C2) and biting rate (C6). Four other criteria have lower impact: vector dispersal capacity (C7), the trophic preferences for Suidae (C8), the probability of contact with domestic pigs (C9) and the probability of contact with wild boar (C10). The cut-off was set to a change in at least three positions in the ranking compared to the ranking based on all ten criteria (represented by the number of crosses in Figure 4).

\subsection{Sensitivity analysis of the impact of experts on the final ranking of blood- feeding arthropods}

The result of this sensitivity analysis indicated that ignoring any expert had only a limited effect on the ranking. However, a change of three ranks was observed for O. moubata and for mosquitoes (genera Aedes, Culex and Anopheles) when some experts were ignored (represented by the number of crosses in Figure 5).

\subsection{Grouping blood-feeding arthropods (BFAs) using regression tree analysis}

Blood-feeding arthropods were grouped into homogenous groups from different families/genera (i.e. terminal nodes) using a regression tree analysis (Figure 6). There groups were identified, in decreasing order of vectorial capacity: Group $1(N=3)$ represented by Stable flies (S. calcitrans), lice (H. suis) and mosquitoes (genera Aedes, Culex and Anopheles); Group $2(N=6)$ represented by Culicoides, Tabanidae, O. moubata, sandflies, hard ticks of the genus Ixodes and fleas, including $C$. felis and P. irritans; and Group $3(N=6)$ represented by hard ticks of the genera Dermacentor, Rhipicephalus, Hyalomma and Haemaphysalis and two species of soft ticks including O. erraticus and $O$. verrucosus.

\section{4 | DISCUSSION}

According to the expert elicitation, two criteria in vectorial capacity appear to be the most important in estimating the potential involvement of BFAs in ASFV transmission in Metropolitan France, being vectorial competence and current vector abundance. Furthermore, the BFAs that have the highest probability to play a role in ASF transmission were identified as being stable flies, lice and mosquitoes. The sensitivity analysis indicated that three criteria have a high impact on the ranking (vectorial competence, current vector abundance and biting rate) but that the diversity of experts involved in the elicitation has a limited effect (acceptable robustness).

The expert elicitation performed during this study showed that stable flies (S. calcitrans), which are the most likely involved in transmitting ASFV in Metropolitan France. Some experimental data highlight the role of stable flies as mechanical vectors of ASF virus. Indeed, as early as the late 1980s, it was demonstrated that stable flies were capable to transmit mechanically ASFV (Mellor et al., 1987). Mellor et al. showed that ASFV was transmitted to susceptible pigs after $S$. calcitrans flies had been infected one hour and $24 \mathrm{hr}$ earlier (titres $10^{3}$ to $10^{5.5} \mathrm{HAD}_{50}{ }^{1} / \mathrm{fly}$ ). ASFV survived in these flies for at least two days without apparent loss of virulence (Mellor et al., 1987). A recent study demonstrated that ASFV DNA remained detectable on the mouthparts of $S$. calcitrans flies for at least $12 \mathrm{hr}$, and for up to three days after infection by in vitro blood feeding in their head and body. Infectious virus was found in the body of the flies at 3 and $12 \mathrm{hr}$ after in vitro infection (Olesen, Hansen, et al., 2018). Infection of pigs with ASFV was demonstrated after ingestion of $S$. calcitrans that had fed on ASFV-spiked blood (Olesen, Lohse, et al., 2018). In addition, the presence of Stomoxys calcitrans and several horsefly species (Haematopota spp., Chrysops spp., Hybomitra spp.) has been recently documented in forest areas frequented by wild boar near to pig farms during the summer period (July-August) (Petrasiunas, Bernotiene, \& Turcinaviciene, 2018). Moreover, several
FIGURE 2 Uncertainty median indexes associated for criteria of the vectorial capacity calculated for different bloodfeeding arthropods (BFAs) considered (box plot based on 14 experts)

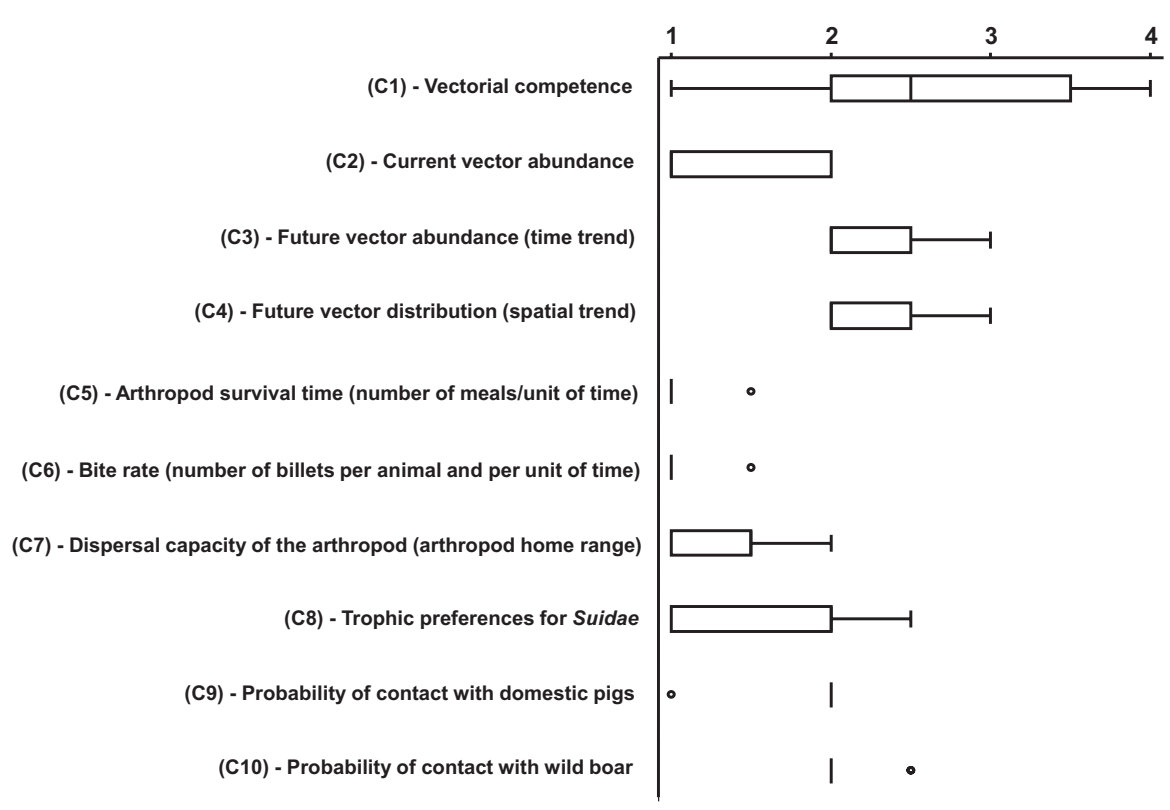




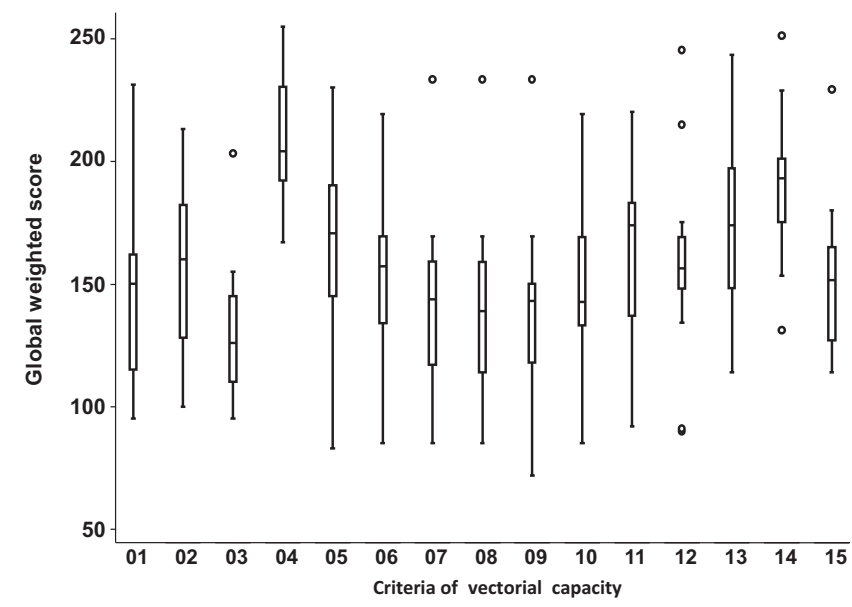

FIGURE 3 Putative vectorial capacity calculated for different blood-feeding arthropods (BFAs) considered (box plot based on 14 experts). $\mathrm{X}$-axis represents the blood-feeding arthropods with the following codification (in brackets): O. erraticus (01), $O$. moubata (02), O. verrucosus (03), Stable flies-Stomoxys calcitrans (04), Tabanidae (05), Ixodes ticks (06), Rhipicephalus Ticks (07), Haemaphysalis Tick (08), Hyalomma Ticks (09), Dermacentor Ticks (10), Culicoides (11), Sandflies (12), Mosquitoes (genera Aedes, Culex and Anopheles) (13), Haematopinus suis (14) and Fleas (C. felis and $P$. irritans) (15). Y-axis represents the global weighted score of vectorial capacity for each BFA. reports indicate the presence of $S$. calcitrans in pig farms including those with high level of biosecurity and around manure (e.g. Fischer et al., 2001; Lempereur et al., 2018; McGarry \& Baker, 1997). In addition, in European context, the maximal capacity of dispersion of S. calcitrans is 150 or 300 metres when partially fed and unfed, respectively (Lempereur et al., 2018), implying a potential pathogens transmission between animals living close-by. However, some publications indicate higher distances of dispersion like hundreds of kilometres in windy conditions (Bailey, Whitfield, \& Smittle, 1973; Hogsette \& Ruff, 1985).

Lice ( $H$. suis) and mosquitoes were also identified as having the highest probability to play a role in ASF transmission. They are among the most abundant vectors known to be able to blood feed on Suidae. Concerning $H$. suis, only one publication mentions the potential role of lice in the experimental transmission of ASFV (Sanchez-Botija and Badiola, 1966). A healthy pig exposed to 50 lice collected from an ASFV-infected pig that had succumbed to the disease, developed leukopenia and died 42 days after the lice infestation. Since this reported experiment was implemented in a single animal, it should be repeated with other exposed pigs to confirm the potential implication of lice in the transmission and the epidemiology of ASFV. Nevertheless, ASF transmission by $\mathrm{H}$. suis is likely to be quite ineffective since these lice are not very mobile and require close contacts between susceptible individuals (e.g. mating, very

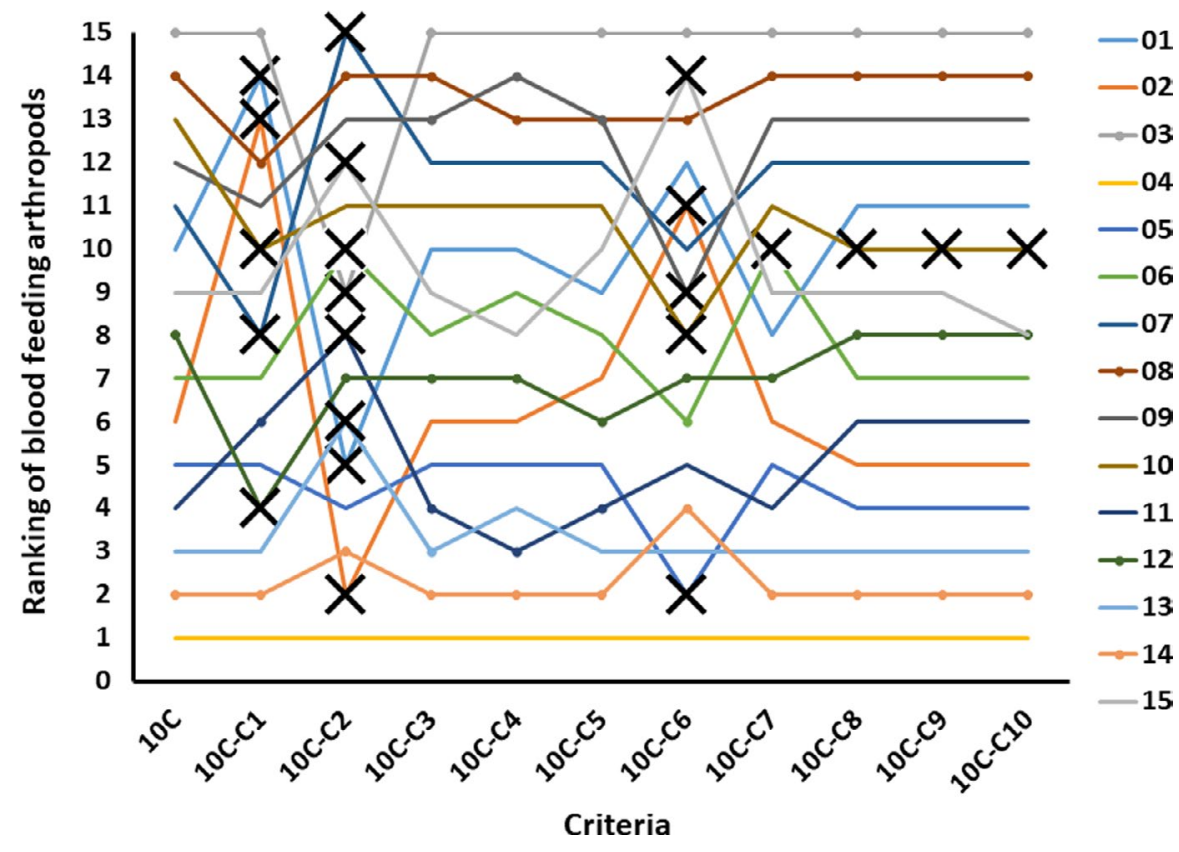

FIGURE 4 Sensitivity analysis according to the criteria of vector capacity. The diagram visualizes modifications in the ranking of bloodfeeding vectors induced by the withdrawal of the given criterion of vectorial capacity. X, crosses represent the cut-off of more than two ranks between different steps. Withdrawal of some criteria (vectorial competence (C1), current vector abundance (C2) and bite rate (C6)) highlights the importance of these criteria leading to the higher cut-off number. X-axis represents the number of criteria considered: $10 \mathrm{C}$, all criteria; $10 \mathrm{C}-\mathrm{C} 1$ to $10 \mathrm{C}-\mathrm{C} 10$, all criteria minus the first (C1), the second (C2), until the last (C10). Y-axis represents the ranking of the BFAs with the following codification: 01 for O. erraticus, 02 for 0 . moubata, 03 for 0 . verrucosus, 04 for stable flies (Stomoxys calcitrans), 05 for Tabanidae, 06 for ticks of the genus Ixodes, 07 for ticks of the genus Rhipicephalus, 08 for ticks of the genus Haemaphysalis, 09 for ticks of the genus Hyalomma, 10 for hard ticks of the genus Dermacentor, 11 for Culicoides, 12 for sandflies, 13 for mosquitoes (genera Aedes, Culex and Anopheles), 14 for lice (H. suis) and 15 for fleas (C. felis and P. irritans). 
high animal density) to move from one animal to another and potentially transmit the virus. Therefore, their role in the transmission of ASFV under field conditions seems possible only in very specific conditions. Concerning mosquitoes, Hameed et al. (2019) showed that mosquitoes of the genera Aedes, Anopheles and Culex could feed on pigs. In another study, ASFV DNA sequences were identified in mosquito samples collected from an Estonian farm where pigs were infected with ASFV (Herm, Tummeleht, Jürison, Vilem, \& Viltrop, 2019). However, these results do not necessarily indicate that mosquitoes can transmit ASFV and further studies on their potential vector role are needed.

Although having a slightly lower median score in the ranking, Culicoides and Tabanidae also need to be considered. Culicoides, ranked fourth in the expert elicitation, have been shown to be able to feed on pigs (Bartsch, Bauer, Wiemann, Clausen, \& Steuber, 2009) and are known to be present in pig farms (Kirkeby, Bodker, Stockmarr, Lind, \& Heegaard, 2013; Oke, Oke, \& Adejinmi, 2017; Zimmer et al., 2008). Assuming that Culicoides are competent vectors for ASFV, it is mainly their high abundance that would contribute to their vectorial capacity. Even if the ASFV was capable of replicating and disseminating in only a limited percentage of a Culicoides vector species (vectorial competence), their high abundance would probably lead to a sufficient number of infected Culicoides to be able to transmit the virus. On the other hand, it should be considered that the volumes of blood collected by a single individual are very small (approximately $0.1 \mu \mathrm{L}$;
Perie, Chermette, Millemann, \& Zientara, 2005), so that a blood meal on a host with low viremia might probably not result in the ingestion of a sufficient dose of virus to initiate replication and spread of the virus in the vector. In case of massive Culicoides infestations, they may also play a role in the mechanical transmission of ASFV. Given their proven role in the transmission of bluetongue virus or Schmallenberg virus (Price \& Hardy, 1954; Rasmussen et al., 2012), further studies are needed to investigate their possible role in ASFV transmission. Unexpectedly, Tabanidae were ranked fifth whereas several authors have suggested that Tabanidae could play a role in ASFV transmission (Costard, Mur, Lubroth, Sanchez-Vizcaino, \& Pfeiffer, 2013; Olesen, Lohse, et al., 2018). Tabanidae are known as strong flyers and readily disperse (Cooksey \& Wright, 1987). They are known also to be mechanical vectors for numerous viral pathogens such as equine infectious anaemia virus, Trypanosoma evansi, Besnotia besnoiti, Bacillus anthracis and Anaplasma marginale (Baldacchino et al., 2014; Krinsky, 1976). They are phototropic and usually do not feed or breed inside dark stables (Foil \& Hogsette, 1994; Middlekauff \& Lane, 1980). They are attracted by semiaquatic forested habitats outside the farms, where they can feed on wild mammals such as wild boar before entering the stables (Herm et al., 2019). They have also been observed near ventilation openings of an ASFVinfected farm in Lithuania (Herm et al., 2019). They could amplify the area of virus spreading, already enhanced by wild boar spatial disturbance due to forestry and leisure activities (Petit

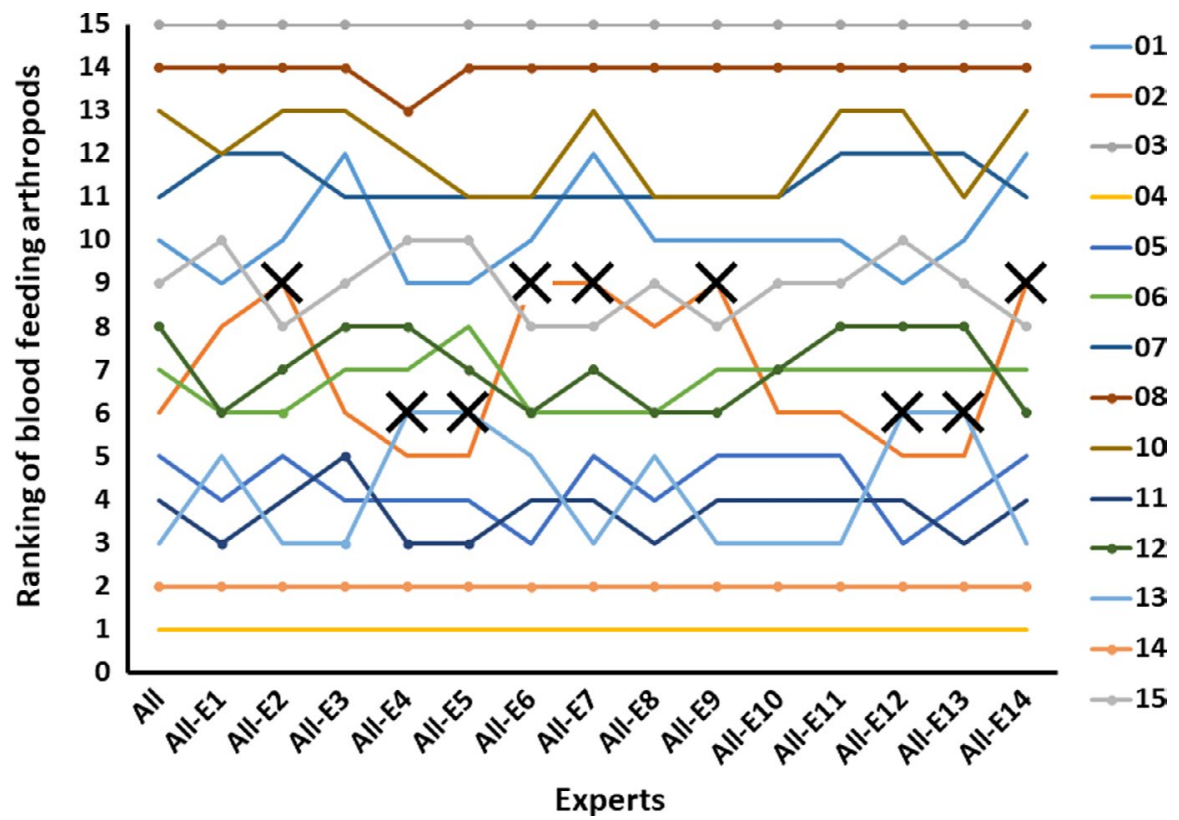

FIGURE 5 Sensitivity analysis according to the experts. The diagram visualizes any modification in the rank of blood-feeding vectors induced by the withdrawal of the input of a given expert. X, crosses represent the cut-off of more than two ranks between different steps. Withdrawal of experts has little effect on the ranking. X-axis represents the expert considered: All, all experts; All-E1 to All-E14 all, experts minus the first (E1), the second (E2), until the last (E14). Y-axis represents the ranking of the BFAs with the following codification: 01 for $O$. erraticus, 02 for 0 . moubata, 03 for O. verrucosus, 04 for stable flies (Stomoxys calcitrans), 05 for tabanidae, 06 for ticks of the genus Ixodes, 07 for ticks of the genus Rhipicephalus, 08 for ticks of the genus Haemaphysalis, 09 for ticks of the genus Hyalomma, 10 for ticks of the genus Dermacentor, 11 for Culicoides, 12 for sandflies, 13 for mosquitoes (genera Aedes, Culex and Anopheles), 14 for lice (H. suis) and 15 for fleas (C. felis, P. irritans). 


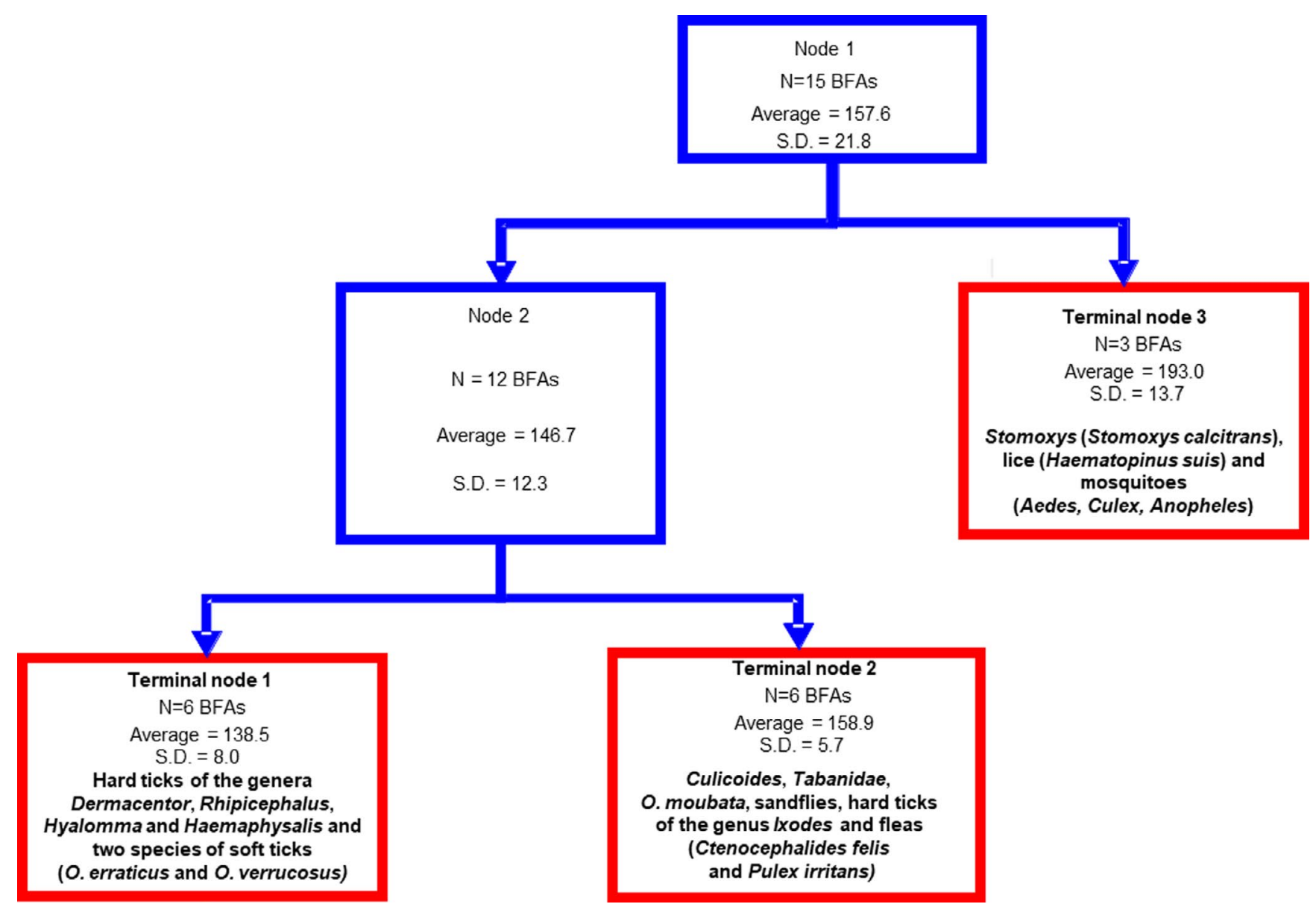

FIGURE 6 Aggregation of blood-feeding vectors into three homogenous groups using a regression tree analysis. N, number; BFAs, bloodfeeding arthropods; SD, standard deviation.

et al., 2019). Due their capacity to ingest important volumes of blood in their large mouthparts, their long blood meals are often interrupted and can involve different hosts. These characteristic make of these insects good potential candidates for mechanical transmission of virus. However, the time interval between blood meals (between five and seven days) is much longer than for stable flies (between four hours and four days), which might be sufficient for the mouthparts to dispose from any residual blood. A possible explanation for the low ranking of Tabanidae in this elicitation could be that they received a low score for vectorial competence and are relatively less abundant (the two top-ranked criteria) than the other arthropods considered in this study. Since these were two top-ranked criteria to determine the vectorial capacity for ASF, it could have strongly influenced their ranking. Thus, further studies are needed to better understand their potential role in transmitting ASFV among Suidae.

One limitation that should be considered for the interpretation of these results is the relatively small number of experts with appropriate knowledge or field experience that could be recruited over a short period of time $(n=14)$. However, this number was sufficient to weight the relative importance of criteria of vectorial capacity and rank the BFAs of importance in Metropolitan France. It would be interesting to scale up this study at the European level, with a broader group of experts (appendixes can be used for this purpose).

Given the limited experimental data on vectorial competence of the different BFA assessed in our study, the lack of data on the presence and abundance of BFAs in habitats shared by wild and domestic Suidae and their trophic preferences, and the lack of knowledge on important biological aspects of blood feeding under field conditions, several research recommendations are proposed:

- To monitor the possible introduction of the soft tick O. erraticus into Metropolitan France from the Iberian peninsula (e.g. Pietschmann et al., 2016);

- To study the vectorial competence of different BFAs;

- To study the persistence of ASFV in and on BFAs by viral isolation to assess its infectiousness over time (e.g. biting flies, mosquitoes);

- To evaluate the infectious dose of ASFV that a BFA is capable of inoculating or transporting (e.g., Niederwerder et al., 2019);

- To develop knowledge on the control of BFAs in farms: insecticide control-with its limitations-and alternative control (e.g. trapping, repellent, growth regulator, use of parasitoïds);

- To evaluate the infection rate of stable flies in currently infected areas, in order to better quantify their potential role in mechanical vector transmission; 
- To determine the species diversity and abundance of Stomoxyinae and Tabanidae present in pig farms;

- To document the presence, abundance and trophic preferences of BFAs present in forest habitats frequented by wild boar (including blood meal analysis).

\section{5 | CONCLUSION}

Limited data are currently available in the literature concerning the putative vectorial capacity of a list of BFAs susceptible to transmit ASFV in the context of Metropolitan France. Consequently, an expert knowledge elicitation was performed by Anses in order to rank 15 BFAs. In the context of Metropolitan France, the stable fly (Stomoxys calcitrans) was ranked first in terms of putative vectorial capacity followed by the pig louse (Haematopinus suis), mosquitoes (genera Aedes, Culex and Anopheles), Culicoides and Tabanidae. However, more studies are requested to investigate this potential role in the transmission of ASFV of the highlighted BFAs in this study, starting with Stomoxys calcitrans.

\section{ACKNOWLEDGEMENTS}

This assessment was conducted by the ad hoc working group 'ASF vectors' of the French Agency for Food, Environmental and Occupational Health \& Safety (Anses). The authors thank all experts who participated in this study. Their names can be found in Appendix S1. We would like to thank Adrienne Pittman, assistant director of the European and International Affairs Department (Anses) for his advices on English.

\section{CONFLICT OF INTEREST}

The authors declare no conflict of interest.

\section{ETHICAL APPROVAL}

Due to the nature of the study and the low risk posed to participants, formal approval from an Ethics Committee was not a requirement at the time of the study.

\section{DATA AVAILABILITY STATEMENT}

The data that support the findings of this study are available from the corresponding author upon reasonable request.

\section{ENDNOTE}

${ }^{1} 50 \%$ haemadsorbing dose.

\section{ORCID}

Claude Saegerman (iD https://orcid.org/0000-0001-9087-7436

Ferran Jori (iD https://orcid.org/0000-0001-5451-7767

Marie-Frédérique Le Potier (iD https://orcid.

org/0000-0003-3929-9129

Timothée Vergne (iD https://orcid.org/0000-0002-1146-9256

Laurence Vial iD https://orcid.org/0000-0002-2341-0147

\section{REFERENCES}

Bailey, D. L., Whitfield, T. L., \& Smittle, B. J. (1973). Flight and dispersal of the stable fly. Journal of Economic Entomology, 66(2), 410-411. https://doi.org/10.1093/jee/66.2.410

Baldacchino, F., Desquesnes, M., Mihok, S., Foil, L. D., Duvallet, G., \& Jittapalapong, S. (2014). Tabanids: Neglected subjects of research, but important vectors of disease agents!. Infection, Genetics and Evolution, 28, 596-615. https://doi.org/10.1016/j.meegid.2014.03.029

Bartsch, S., Bauer, B., Wiemann, A., Clausen, P. H., \& Steuber, S. (2009). Feeding patterns of biting midges of the Culicoides obsoletus and Culicoides pulicaris groups on selected farms in Brandenburg, Germany. Parasitology Research, 105(2), 373-380. https://doi. org/10.1007/s00436-009-1408-y

Breiman, L., Friedman, J. H., Olshen, R. A., \& Stone, C. J. (Eds.) (1984). Classification and regression trees. Pacific Grove (CA): Chapman and Hall Publisher.

Chenais, E., Ståhl, K., Guberti, V., \& Depner, K. (2018). Identification of wild boar-habitat epidemiologic cycle in African swine fever epizootic. Emerging Infectious Diseases, 24(4), 810-812. https://doi. org/10.3201/eid2404.172127

Cooksey, L. M., \& Wright, R. E. (1987). Flight range and dispersal activity of the host-seeking horse fly, Tabanus abactor (Diptera: Tabanidae), in North Central Oklahoma. Environmental Entomology, 16, 211-217. https://doi.org/10.1093/ee/16.1.211

Costard, S., Mur, L., Lubroth, J., Sanchez-Vizcaino, J. M., \& Pfeiffer, D. U. (2013). Epidemiology of African swine fever virus. Virus Research, 173(1), 191-197. https://doi.org/10.1016/j.virusres.2012.10.030

EFSA (2010). Scientific opinion on the role of tick vectors in the epidemiology of crimean-congo hemorrhagic fever and African swine fever in Eurasia. Parma, Italy: European Food Safety Authority (EFSA).

EFSA (2018). Epidemiological analyses of African swine fever in the European Union. Parma, Italy: European Food Safety Authority (EFSA). (November 2017 until November 2018).

Estrada-Peña, A., Gray, J. S., Kahl, O., Lane, R. S., \& Nijhof, A. M. (2013). Research on the ecology of ticks and tick-borne pathogens-methodological principles and caveats. Frontiers in Cellular and Infection Microbiology, 3, 29. https://doi.org/10.3389/fcimb.2013.00029

Fasina, F. O., Lazarus, D. D., Spencer, B. T., Makinde, A. A., \& Bastos, A. D. (2012). Cost implications of African swine fever in smallholder farrow-to-finish units: Economic benefits of disease prevention through biosecurity. Transboundary and Emerging Diseases, 59(3), 244-255. https://doi.org/10.1111/j.1865-1682.2011.01261.x

Fischer, O., Mátlová, L., Dvorská, L., Svástová, P., Bartl, J., Melichárek, I., ... Pavlík, I. (2001). Diptera as vectors of mycobacterial infections in cattle and pigs. Medical and Veterinary Entomology, 15(2), 208-211. https://doi.org/10.1046/j.1365-2915.2001.00292.x

Foil, L. D., \& Hogsette, J. A. (1994). Biology and control of tabanids, stable flies and horn flies. Revue Scientifique Et Technique (International Office of Epizootics), 13, 1125-1158. https://doi.org/10.20506/ rst.13.4.821

Galindo, I., \& Alonso, C. (2017). African swine fever virus: A review. Viruses, 9(5), E103. https://doi.org/10.3390/v9050103

Garigliany, M., Desmecht, D., Tignon, M., Cassart, D., Lesenfant, C., Paternostre, J., ... Linden, A. (2019). Phylogeographic analysis of African swine fever virus, Western Europe, 2018. Emerging Infectious Diseases, 25(1), 184-186. https://doi.org/10.3201/eid2501.181535

Golnar, A. J., Martin, E., Wormington, J. D., Kading, R. C., Teel, P. D., Hamer, S. A., \& Hamer, G. L. (2019). Reviewing the potential vectors and hosts of African swine fever virus transmission in the United States. Vector-Borne and Zoonotic Diseases, 19(7), 512-524. https:// doi.org/10.1089/vbz.2018.2387

Gore, S. M. (1987). Biostatistics and the Medical Research Council. MRC News, 35, 19-20.

Gubbins, S., Carpenter, S., Baylis, M., Wood, J. L., \& Mellor, P. S. (2008). Assessing the risk of bluetongue to UK livestock: Uncertainty and 
sensitivity analyses of a temperature-dependent model for the basic reproduction number. Journal of the Royal Society, Interface, 5(20), 363-371. https://doi.org/10.1098/rsif.2007.1110

Guinat, C., Gogin, A., Blome, S., Keil, G., Pollin, R., Pfeiffer, D. U., \& Dixon, L. (2016). Transmission routes of African swine fever virus to domestic pigs: Current knowledge and future research directions. The Veterinary Record, 178(11), 262-267. https://doi.org/10.1136/ vr.103593

Halasa, T., Bøtner, A., Mortensen, S., Christensen, H., Toft, N., \& Boklund, A. (2016). Simulating the epidemiological and economic effects of an African swine fever epidemic in industrialized swine populations. Veterinary Microbiology, 193, 7-16. https://doi.org/10.1016/j. vetmic.2016.08.004

Hameed, M., Liu, K., Anwar, M. N., Wahaab, A., Li, C., Di, D., ... Ma, Z. (2019). A viral metagenomic analysis reveals rich viral abundance and diversity in mosquitoes from pig farms. Transboundary and Emerging Diseases, https://doi.org/10.1111/tbed.13355

Herm, R., Tummeleht, L., Jürison, M., Vilem, A., \& Viltrop, A. (2020). Trace amounts of African swine fever virus DNA detected in insects collected from an infected pig farm in Estonia. Veterinary Medicine and Science, 6(1), 100-104. https://doi.org/10.1002/vms3.200.

Hogsette, J., \& Ruff, J. P. (1985). Stable fly (Diptera: Muscidae) migration in Northwest Florida. Environmental Entomology, 14(2), 170-175. https://doi.org/10.1093/ee/14.2.170

Humblet, M. F., Vandeputte, S., Albert, A., Gosset, C., Kirschvink, N., Haubruge, E., \& Saegerman, C. (2012). Multidisciplinary and evidence-based method for prioritizing diseases of food-producing animals and zoonoses. Emerging Infectious Diseases, 18(4), https://doi. org/10.3201/eid1804.111151.

Kirkeby, C., Bodker, R., Stockmarr, A., Lind, P., \& Heegaard, P. M. (2013). Quantifying dispersal of European culicoides (Diptera: Ceratopogonidae) vectors between farms using a novel mark-release-recapture technique. PLoS One, 8(4), e61269. https://doi.org/10.1371/journal.pone.0061269

Krinsky, W. L. (1976). Animal disease agents transmitted by horse flies and deer flies (Diptera: Tabanidae). Journal of Medical Entomology, 13, 225-275. https://doi.org/10.1093/jmedent/13.3.225

LaDeau, S. L., Allan, B. F., Leisnham, P. T., \& Levy, M. Z. (2015). The ecological foundations of transmission potential and vector-borne disease in urban landscapes. Functional Ecology, 29, 889-901. https:// doi.org/10.1111/1365-2435.12487

Lempereur, L., Sohier, C., Smeets, F., Maréchal, F., Berkvens, D., Madder, M., ... Losson, B. (2018). Dispersal capacity of Haematopota spp. and Stomoxys calcitrans using a mark-release-recapture approach in Belgium. Medical and Veterinary Entomology, 32(3), 298-303. https:// doi.org/10.1111/mve.12297

McGarry, J. W., \& Baker, A. S. (1997). Observations on the mite fauna associated with adult Stomoxys calcitrans in the U.K. Medical and Veterinary Entomology, 11(2), 159-164. https://doi. org/10.1111/j.1365-2915.1997.tb00307.x

Mellor, P. S., Kitching, R. P., \& Wilkinson, P. J. (1987). Mechanical transmission of capripox virus and African swine fever virus by Stomoxys calcitrans. Research in Veterinary Science, 43(1), 109-112. https://doi. org/10.1016/S0034-5288(18)30753-7

Middlekauff, W. W., \& Lane, R. S. (1980). Adult and immature Tabanidae (Diptera) of California. Bulletin of the California Insect Survey, 22, 1-99.

Mulumba-Mfumu, L. K., Saegerman, C., Dixon, L. K., Madimba, K. C., Kazadi, E., Mukalakata, N. T., ... Penrith, M. L. (2019). African swine fever: Update on Eastern, Central and Southern Africa. Transboundary and Emerging Diseases, 66(4), 1462-1480. https://doi.org/10.1111/ tbed.13187

Nash, T. A. M. (1944). A low density of tsetse flies associated with a high incidence of sleeping sickness. Bulletin of Entomological Research, 35(1), 51. https://doi.org/10.1017/S0007485300005630

Niederwerder, M. C., Stoian, A. M. M., Rowland, R. R. R., Dritz, S. S., Petrovan, V., Constance, L. A., ... Hefley, T. J. (2019). Infectious dose of African swine fever virus when consumed naturally in liquid or feed. Emerging Infectious Diseases, 25(5), 891-897. https://doi. org/10.3201/eid2505.181495

Oke, P. O., Oke, B. E., \& Adejinmi, J. O. (2017). Swine farm infestation with Culicoides species (biting midges) in Zaria, Nigeria. Sokoto Journal of Veterinary Sciences, 15(2), 66-69. https://doi.org/10.4314/sokjvs. v15i2.10

Olesen, A. S., Hansen, M. F., Rasmussen, T. B., Belsham, G. J., Bødker, R., $\&$ Bøtner, A. (2018). Survival and localization of African swine fever virus in stable flies (Stomoxys calcitrans) after feeding on viremic blood using a membrane feeder. Veterinary Microbiology, 222, 25-29. https://doi.org/10.1016/j.vetmic.2018.06.010

Olesen, A. S., Lohse, L., Hansen, M. F., Boklund, A., Halasa, T., Belsham, G. J., ... Bødker, R. (2018). Infection of pigs with African swine fever virus via ingestion of stable flies (Stomoxys calcitrans). Transboundary and Emerging Diseases, 65(5), 1152-1157. https://doi.org/10.1111/ tbed.12918

Pautienius, A., Grigas, J., Pileviciene, S., Zagrabskaite, R., Buitkuviene, J., Pridotkas, G., ... Stankevicius, A. (2018). Prevalence and spatiotemporal distribution of African swine fever in Lithuania, 20142017. Virology Journal, 15(1), 177. https://doi.org/10.1186/s1298 5-018-1090-8

Pereira de Oliveira, R., Hutet, E., Paboeuf, F., Duhayon, M., Boinas, F., Perez de Leon, A., ... Le Potier, M. F. (2019). Comparative vector competence of the Afrotropical soft tick Ornithodoros moubata and Palearctic species, O. erraticus and $O$. verrucosus, for African swine fever virus strains circulating in Eurasia. PLoS One, 14(11), e0225657. https://doi.org/10.1371/journal.pone.0225657

Perie, P., Chermette, R., Millemann, Y., \& Zientara, S. (2005). Culicoides, hematophagous Diptera vectors of Bluetongue disease. Bulletin De L'académie Vétérinaire De France, 158(3), 213-224. https://doi. org/10.4267/2042/47770

Petit, K., Dunoyer, C., Fischer, C., Hars, J., Baubet, E., López-Olvera, J. R., ... Saegerman, C. (2020). Assessment of the impact of forestry and leisure activities on wild boar spatial disturbance with a potential application to ASF risk of spread. Transboundary and Emerging Diseases, 67(3), 1164-1176. https://doi.org/10.1111/tbed.13447.

Petrasiunas, A., Bernotiene, R., \& Turcinaviciene, J. (2018). Catches of blood-feeding flies with NZI traps in African Swine Fever affected areas of Lithuania. Bulletin of the Lithuanian Entomological Society, 2(30), 112-118.

Pietschmann, J., Mur, L., Blome, S., Beer, M., Pérez-Sánchez, R., Oleaga, A., \& Sánchez-Vizcaíno, J. M. (2016). African swine fever virus transmission cycles in Central Europe: Evaluation of wild boar-soft tick contacts through detection of antibodies against Ornithodoros erraticus saliva antigen. BMC Veterinary Research, 12, 1. https://doi. org/10.1186/s12917-015-0629-9

Plateforme ESA (2019). Bulletin hebdomadaire de veille santé animale du 17/12/2019. Accessed at 22 December 2019, URL: https://www. plateforme-esa.fr/bulletin-hebdomadaire-de-veille-sante-anima le-du-17-12-2019

Podgorski, T., \& Smietanka, K. (2018). Do wild boar movements drive the spread of African swine fever? Transboundary and Emerging Diseases, 65(6), 1588-1596. https://doi.org/10.1111/tbed.12910

Price, D. A., \& Hardy, W. T. (1954). Isolation of the bluetongue virus from Texas sheep-Culicoides shown to be a vector. Journal of the American Veterinary Medical Association, 124(925), 255-258.

Rasmussen, L. D., Kristensen, B., Kirkeby, C., Rasmussen, T. B., Belsham, G. J., Bødker, R., \& Bøtner, A. (2012). Culicoids as vectors of Schmallenberg virus. Emerging Infectious Diseases, 18(7), 1204-1206. https://doi.org/10.3201/eid1807.120385

Rodhain, F. (1985). Arbovirus-vector relations. Bulletin De La Societe De Pathologie Exotique Et De Ses Filiales, 78(5), 763-768.

Rodhain, F. (1991). Le fonctionnement des systèmes virus-vecteurs. Annales De La Société Belge De Médecine Tropicale, 71(1), 189-199. 
Rowlands, R. J., Michaud, V., Heath, L., Hutchings, G., Oura, C., Vosloo, W., ... Dixon, L. K. (2008). African swine fever virus isolate, Georgia, 2007. Emerging Infectious Diseases, 14(12), 1870-1874. https://doi. org/10.3201/eid1412.080591

Saegerman, C. (2018). Découverte inattendue de la peste porcine africaine en Belgique. Epidémiologie Et Santé Animale, 73, 147-164.

Saegerman, C., Berkvens, D., \& Mellor, P. S. (2008). Bluetongue epidemiology in the European Union. Emerging Infectious Diseases, 14(4), 539-544. https://doi.org/10.3201/eid1404.071441

Saegerman, C., Porter, S. R., \& Humblet, M. F. (2011). The use of modelling to evaluate and adapt strategies for animal disease control. Revue Scientifique Et Technique, 30(2), 555-569. https://doi.org/10.20506/rst.30.2.2048

Sanchez-Botija, C., \& Badiola, C. (1966). Presencie of the African swine pest virus in Haematopinus suis. Bulletin-Office International Des Epizooties, 66(1), 699-705.

Sanchez-Botija, C. (1963). Reservorios del virus de la peste porcina Africana. Investigacion del virus la P.P.A en los artropodos mediante la prueba de la hemoadsorcion. Bulletin-Office International Des Epizooties, 60, 895-899.

Sánchez-Vizcaíno, J. M., Mur, L., \& Martínez-López, B. (2013). African swine fever (ASF): Five years around Europe. Veterinary Microbiology, 165(1-2), 45-50. https://doi.org/10.1016/j.vetmic.2012.11.030
Schulz, K., Conraths, F. J., Blome, S., Staubach, C., \& Sauter-Louis, C. (2019). African swine fever: Fast and furious or slow and steady? Viruse, 11(9), E866. https://doi.org/10.3390/v11090866

Zimmer, J. Y., Haubruge, E., Francis, F., Bortels, J., Joie, E., Simonon, G., ... Kirschvink, N. (2008). Distribution of potential bluetongue vectors on Belgium farms. The Veterinary Record, 162(21), 700. https://doi. org/10.1136/vr.162.21.700

\section{SUPPORTING INFORMATION}

Additional supporting information may be found online in the Supporting Information section.

How to cite this article: Saegerman C, Bonnet S, Bouhsira E, et al. An expert opinion assessment of blood-feeding arthropods based on their capacity to transmit African swine fever virus in Metropolitan France. Transbound Emerg Dis. 2020;00:1-15. https://doi.org/10.1111/tbed.13769 